OPEN ACCESS

Edited by: Fermin I. Milagro, University of Navarra, Spain

Reviewed by: Brian Neal Finck, Washington University in St. Louis, United States Scott Widenmaier University of Saskatchewan, Canada

*Correspondence: Karin G. Stenkula karin.stenkula@med.lu.se

Specialty section: This article was submitted to Lipid and Fatty Acid Research, a section of the journal Frontiers in Physiology

Received: 13 July 2021 Accepted: 25 August 2021 Published: 24 September 2021

Citation:

Fryklund C, Morén B, Shah S, Grossi $M$, Degerman $E$ Matthaeus $C$ and Stenkula KG (2021) EH Domain-Containing 2 Deficiency Restricts Adipose Tissue Expansion and Impairs Lipolysis in Primary Inguinal Adipocytes.

Front. Physiol. 12:740666. doi: 10.3389/fphys.2021.740666

\section{EH Domain-Containing 2 Deficiency Restricts Adipose Tissue Expansion and Impairs Lipolysis in Primary Inguinal Adipocytes}

\author{
Claes Fryklund ${ }^{1}$, Björn Morén ${ }^{1}$, Shrenika Shah ${ }^{2}$, Mario Grossi ${ }^{1}$, Eva Degerman ${ }^{1}$, \\ Claudia Matthaeus ${ }^{3}$ and Karin G. Stenkula ${ }^{1 *}$
}

${ }^{1}$ Department of Experimental Medical Science, Lund University, Lund, Sweden, ${ }^{2}$ School of Biomedical, Nutritional and Sport Sciences, Newcastle University, Newcastle upon Tyne, United Kingdom, ${ }^{3}$ National Heart, Lung and Blood Institute, NIH, Bethesda, MD, United States

Lipid uptake can be facilitated via caveolae, specific plasma membrane invaginations abundantly expressed in adipocytes. The dynamin-related protein EH domain-containing 2 (EHD2) stabilizes caveolae at the cell surface. Here, we have examined the importance of EHD2 for lipid handling using primary adipocytes isolated from EHD2 knockout (Ehd2 ${ }^{-/-}$) C57BL6/N mice. Following high-fat diet (HFD) feeding, we found a clear impairment of

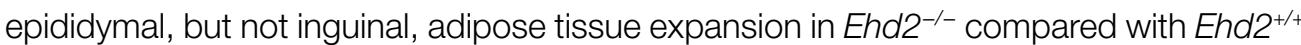
(WT) mice. Cell size distribution analysis revealed that Ehd2 ${ }^{-1-}$ mice had a lower proportion of small adipocytes, and an accumulation of medium-sized adipocytes in both epididymal and inguinal adipose tissue. Further, PPAR $\gamma$ activity, FABP4 and caveolin-1 expression were decreased in adipocytes isolated from Ehd2 ${ }^{-/-}$mice. Inguinal adipocytes isolated from Ehd $2^{-/-}$mice displayed reduced lipolysis in response to beta adrenergic receptor agonist, which was associated with reduced phosphorylation of perilipin-1 and hormone sensitive lipase (HSL). This impairment could not be rescued using a cAMP analog, indicating that impaired lipolysis in Ehd $2^{-/-}$primary adipocytes likely occurs at the level of, or downstream of, protein kinase $A(P K A)$. Altogether, these findings pinpoint the importance of EHD2 for maintained intracellular lipid metabolism, and emphasize differences in mechanisms regulating lipid handling in various adipose-tissue depots.

Keywords: adipocytes, EH domain-containing 2, caveolae, fatty acids, adipose tissue

\section{INTRODUCTION}

There is a global rise in obesity, and it is estimated that $38 \%$ of the population will have overweight by year 2030. During excess calorie intake, both hypertrophy and hyperplasia of adipocytes occur, ultimately causing adipose tissue expansion (Faust et al., 1978; Li et al., 2016). Adipocyte size predicts development of type 2 diabetes (Weyer et al., 2000; Acosta et al., 2016) and sustained overconsumption of calories leads to an accumulation of hypertrophic adipocytes 
that are less responsive to insulin (Salans et al., 1968; Salans and Dougherty, 1971; Smith, 1972; Franck et al., 2007). Impaired differentiation (Grunberg et al., 2014; Acosta et al., 2016) and a limited ability of adipocytes to expand further (McLaughlin et al., 2007) could contribute to adipose tissue dysfunction. Notably, the adipogenic potential varies in different adipose tissue depots (Wang et al., 2013; Jeffery et al., 2015). For example, a restricted capacity to increase the subcutaneous adipose tissue is hypothesized to favor expansion of visceral adipose tissue and underlie progression toward metabolic disorders (Wajchenberg, 2000; McLaughlin et al., 2011; Shulman, 2014).

Caveolae are specific invaginations of the plasma membrane (Palade, 1953; Yamada, 1955). These specialized domains orchestrate lipid transport (Razani et al., 2002; Pohl et al., 2005; Meshulam et al., 2006; Liu et al., 2008), and via interaction with the caveolar core protein caveolin, caveolae scaffold various signaling molecules, including endothelial nitric oxide synthase (eNOS; Garcia-Cardena et al., 1996), tyrosine kinase receptors (Gustavsson et al., 1999), and G-protein coupled receptors (Schwencke et al., 1999; Insel et al., 2005). Ablation or mutation of caveolins, or caveolae depletion, lead to impaired insulin signaling in adipose tissue (Gustavsson et al., 1999; Cohen et al., 2003) and lipodystrophy in rodent models (Razani et al., 2002; Liu et al., 2008) and human (Cao et al., 2008; Kim et al., 2008). Indeed, caveolin-1 deficient mice were resistant to diet-induced obesity (Razani et al., 2002). EH domaincontaining 2 (EHD2) is a dynamin-related ATPase (Daumke et al., 2007) that localizes at the neck of caveolae, where it is proposed to regulate the stability of caveolae at the plasma membrane (Moren et al., 2012; Stoeber et al., 2012; Ludwig et al., 2013). Further studies have addressed caveolae as a membrane reservoir, where EHD2 serves as a mechanosensor, and via translocation to the nuclei connects caveolae with transcriptional activity (Torrino et al., 2018). Recently, we identified Ehd 2 as one of the most highly upregulated genes in adipose tissue after short-term overfeeding in mice (Hansson et al., 2018). In a follow-up study, we demonstrated that EHD2 associates and drives the formation of cell surfaceproximal lipid droplets in adipocytes, sustains in vitro adipogenesis and enhances lipolytic activity (Moren et al., 2019). In line with our results, EHD2 was confirmed to affect lipid metabolism in Ehd2 $2^{-/-}$mice (Matthaeus et al., 2020). In that study, EHD2 deficiency led to caveolae detachment and increased fatty acid uptake, reinforcing the role of caveolae for lipid transport.

Even though caveolae are undoubtedly involved in lipid metabolism, the specific mechanisms are currently not understood. While recent studies have addressed EHD2 to play a role in lipid handling, it is unclear how EHD2 deficiency affects these events in primary adipocytes. Furthermore, it is unknown if EHD2 influences gene transcription activity that is essential to sustain adipose tissue expansion. To address this, we have characterized adipose cell size distribution and lipolysis in primary adipocytes isolated from $E h d 2^{-/-}$mice challenged with high-fat diet (HFD) feeding. We demonstrate that EHD2 is necessary for both adipose tissue expansion and for maintenance of lipolysis in primary adipocytes.

\section{MATERIALS AND METHODS}

\section{Material}

Adipose triglyceride lipase (ATGL; \#2138), caveolin-1 (\#3267S), FABP4 (\#3544S), hormone sensitive lipase (HSL) pS563 (\#4139), CREB pS133 (\#9191S) and pPKA motif specific [P-RXX(S/T); \#9624S] antibodies were from Cell Signaling Technologies (Danvers, United States). Heat shock protein (HSP) 90 (\#610418) antibody was from BD Transduction Laboratories (Franklin Lakes, United States). Perilipin-1 total (\#4854) and pS522 (\#4856) antibodies from Vala Science (San Diego, United States). Antibody against EHD2 (\#154784) was from Abcam (Cambridge, United Kingdom). Total HSL antibody was kindly provided by Cecilia Holm (Lund University). Fluorescenceconjugated (Alexa Fluor) secondary antibodies, Bodipy 493/503 (D3922), and MitoTracker RED CMXRos (M7512) were purchased from Molecular Probe (Waltham, United States). Rosiglitazone (R2408) was from Sigma-Aldrich (St. Louis, United States). The PPRE-x3-TK-Luc reporter plasmid was a kind gift from Bruce Spiegelman (Addgene plasmid \#1015) and Renilla Luciferase Control Reporter (pRLnull; \#E227A) from Promega (Madison, United States). Reagent for determination of glycerol content (F6428) and dibutyryl-cAMP (DcAMP; \#D0627) were from Sigma-Aldrich (St. Louis, United States). PDE3 inhibitor OPC3911 and PDE4 inhibitor Rolipram were from Otsuka Pharmaceuticals (Tokyo, Japan) and PDE3B antibody was produced in-house.

\section{Animals}

C57BL6/N mice with global deletion of exon 3 of the Ehd2 gene $\left(E h d 2^{-/-}\right)$as described (Matthaeus et al., 2020) were kindly provided by Oliver Daumke (MDC, Germany). Genotyping was carried out to confirm deletion of the Ehd2 gene. Ehd2 $2^{-1-}$ and $\mathrm{Ehd}^{+/+} \mathrm{C} 57 \mathrm{BL6} / \mathrm{N}$ mice (the latter used as WT control) were bred in parallel to generate sufficient number of animals for cellular analysis. Animals were on a $12 \mathrm{~h}$ light cycle with non-restricted food and water. Mice were fed either chow or HFD (D12492 60 E\% fat content; Research Diets, New Brunswick, United States).

\section{Ethics Statement}

All animal procedures were approved by the Malmö/Lund Committee for Animal Experiment Ethics, Lund, Sweden, and were carried out in accordance with the relevant guidelines and regulations.

\section{Adipocyte Isolation}

Primary adipocytes were isolated from different adipose tissue depots using previously established protocol (Rodbell, 1964). Isolated, primary adipocytes were suspended $10 \%(\mathrm{v} / \mathrm{v})$ in Krebs Ringer Bicarbonate HEPES (KRBH) buffer, $\mathrm{pH} 7.4$, containing $200 \mathrm{nM}$ adenosine and $3 \%(\mathrm{w} / \mathrm{v})$ bovine serum albumin (BSA).

\section{Western Blot}

Following incubations, cells were washed with KRH medium without BSA and subsequently lysed in a buffer containing 
$50 \mathrm{mM}$ Tris/HCl pH 7.5, $1 \mathrm{mM}$ EGTA, $1 \mathrm{mM}$ EDTA, $0.27 \mathrm{M}$ sucrose, $1 \% \mathrm{NP}-40$, and complete protease- and phosphatase inhibitor cocktail (Roche, Basel, Switzerland). Lysates were centrifuged for $10 \mathrm{~min}$ at $13,000 \times g$ and protein concentrations were determined using the Bradford method. Samples were subjected to polyacrylamide gel electrophoresis and electrotransfer to nitrocellulose membranes. Membranes were blocked with non-fat dry milk $[10 \%(\mathrm{w} / \mathrm{v})]$ and probed with the indicated antibodies. Detection was performed using horseradish peroxidase conjugated secondary antibodies and enhanced chemiluminescence reagent. The signal was visualized using a BioRad Image camera (Biorad, Hercules, United States).

\section{Plasmid Transfection and Luciferase Activity Assays}

Adipocytes were transfected as previously described (Lizunov et al., 2013). In short, isolated adipose cells were suspended $[40 \%(\mathrm{v} / \mathrm{v})]$ in DMEM supplemented with Gentamicin $(20 \mu \mathrm{g} / \mathrm{ml})$ and $200 \mathrm{nM}$ phenylisopropyladenosine (PIA). Cells were electroporated using a square-wave pulse; $400 \mathrm{~V}, 12 \mathrm{~ms}$, one pulse (Harvard Apparatus, Holliston, United States) with PPRE reporter and pRLnull (normalization) plasmids (10:1). After electroporation, the cells were transferred into DMEM with Gentamicin $(20 \mu \mathrm{g} / \mathrm{ml})$, PIA and [3.5\% (w/v)] BSA and cultured for $24 \mathrm{~h}$ at $37^{\circ} \mathrm{C}$ in $5 \% \mathrm{CO}_{2}$. Thereafter, the cells were lysed in Promega passive lysis buffer, and the lysates centrifuged at $10,000 \times \mathrm{g}$ for $10 \mathrm{~min}$ at $4^{\circ} \mathrm{C}$ to separate the protein lysate (infranatant) from the fat. Luciferase activity was measured in a Glomax luminometer (Promega) using the Dual Luciferase Reporter system (Promega), where data were normalized to Renilla reporter (pRLnull).

\section{Fluorescence Microscopy}

Imaging was performed using a Nikon A1 plus confocal microscope with a $60 \times$ Apo DIC oil immersion objective with a NA of 1.40 (Nikon Instruments) and appropriate filter sets. Images were acquired with NIS-Elements, version: 4.50 .02 (Laboratory Imaging). Isolated cells were fixed using $4 \%$ paraformaldehyde (PFA) and labeled with antibodies in a buffer containing $1 \%$ BSA, $1 \%$ goat serum, and $0.05 \%$ saponin $1-2 \mathrm{~h}$. For neutral lipid staining, cells were stained with Bodipy 493/503 and for mitochondria we used Mitotracker. For imaging of primary adipocytes, we used previously described protocol (Wasserstrom et al., 2018).

\section{Electron Microscopy}

For standard trans-electron microscopy, adipose tissue was fixed overnight using 1\% PFA and 3\% glutaraldehyde, followed by dehydration using methanol series $(20,40,60,80$, and $100 \%)$ $30 \mathrm{~min}$ each, de-lipidated using dichloromethane for $1 \mathrm{~h}$, and then rehydrated with reverse methanol series. Methanol was diluted in $\mathrm{KRBH}$ without BSA. The samples were fixed using osmium-tannic acid-osmium (OTO) for $1 \mathrm{~h}$ each, washed in $\mathrm{KRBH}$ without BSA, dehydrated using ethanol series and embedded in EPON.

\section{Lipolysis}

Lipolysis was determined by measuring glycerol release, as described previously (Hansson et al., 2016). In short, cells [10\% (v/v) cell suspension] were treated with or without isoprenaline (ISO; $10 \mathrm{nM})$, or a combination of insulin $(1 \mathrm{nM})$ and ISO $(10 \mathrm{nM})$ for $30 \mathrm{~min}$. Cell medium was subsequently removed for enzymatic determination of the glycerol content. In short, $100 \mu \mathrm{l}$ free glycerol reagent was added to $30 \mu \mathrm{l}$ sample. Absorbance at $540 \mathrm{~nm}$ was measured after incubating for $\sim 15 \mathrm{~min}$ at room temperature. Each sample was analyzed in duplicate. In a separate set of experiments, cells were pre-incubated $(10 \mathrm{~min})$ with OPC3911 $(10 \mu \mathrm{M})$, Rolipram $(10 \mu \mathrm{M})$ or DMSO $0.1 \%$ (control), followed by $30 \mathrm{~min}$ stimulation with or without ISO $(10 \mathrm{nM})$ or a combination of insulin $(1 \mathrm{nM})$ and ISO $(10 \mathrm{nM})$. For experiments where DcAMP was used, cells were pre-incubated for $10 \mathrm{~min}$ and then treated with or without ISO $(10$ or $1,000 \mathrm{nM})$ or DcAMP $(100$ or $1,000 \mu \mathrm{M})$ for $30 \mathrm{~min}$. Glycerol release was measured as stated above.

\section{RT-qPCR}

Total RNA was extracted using miRNeasy mini kit (Qiagen \#74104). RNA purity and concentration were assessed using a Nanodrop spectrophotometer (Thermo Scientific). PCR-reactions were performed using the Quantifast SYBR Green RT-PCR kit (Qiagen \#204156) and Quantitect primer assays for 18S, Adrb3, Ehd2, and Plin1. Primer sequences are considered proprietary information by Qiagen. mRNA expression levels were measured using a StepOnePlus real-time thermal cycler (Applied Biosystems Waltham, United States) and quantitated using the $\Delta \Delta \mathrm{C}_{\mathrm{T}}$ method as described by Livak and Schmittgen (2001). 18S rRNA was used for normalization throughout.

\section{Cell Size Distribution}

Adipose tissue samples were obtained from epididymal (EPI) and ING adipose depots. The adipose cell-size distributions were obtained using a Beckman-Coulter counter after osmium fixation as described previously (Li et al., 2016).

\section{Liver Triglyceride Content}

To determine the liver triglyceride concentration, $\sim 100 \mathrm{mg}$ frozen liver sample was homogenized using a motorized homogenizer in buffer containing $5 \%(\mathrm{w} / \mathrm{v})$ NP-40. The homogenized samples were heated at $90^{\circ} \mathrm{C}$ for $3 \mathrm{~min}$, cooled down for $15 \mathrm{~min}$ in room temperature, reheated at $90^{\circ} \mathrm{C}$ for $3 \mathrm{~min}$, and then centrifuged at maximum speed for $2 \mathrm{~min}$ at $20^{\circ} \mathrm{C}$. The supernatant was collected and placed in a 96-well plate with triglyceride reagent (Thermo Scientific) for triglyceride concentration determination.

\section{Blood Analyses}

Terminal serum samples were collected and blood glucose levels measured using OnetouchUltra2 (Lifescan, Milpitas, United States), and insulin levels assayed in serum using ELISA from Mercodia (Uppsala, Sweden). Serum concentration of free fatty acid (FFA) was measured using FFA assay kit (\#ab65341) from Abcam (Cambridge, United Kingdom). 


\section{Oil Red-O Staining}

Cut frozen sections $(5 \mu \mathrm{m})$ were fixed with $4 \%$ PFA and incubated for $10 \mathrm{~min}$ at room temperature. Excess of $4 \%$ PFA was removed by three rinses in PBS. Subsequently, the sections were rinsed with $60 \%$ isopropanol and then stained with freshly and filtrated oil Red-O working solution [ $30 \mathrm{ml}$ of $0.5 \%$ ORO (O0625, Sigma; Saint Louis, United States) stock solution $+20 \mathrm{ml}$ distilled water] for $20 \mathrm{~min}$ at room temperature. After the sections were rinsed with $60 \%$ isopropanol and then washed with distilled water and covered with a coverslip using permanent aqueous mounting medium (BUF058A, Biorad). Images were captured using an Olympus BX60 microscope.

\section{Statistical Analysis}

Analysis was performed by unpaired two-tailed Student's $t$-test or one-way ANOVA, Tukey's post hoc test using GraphPad Prism 6 (Graphpad Software Inc.) software. Significance was determined according to ${ }^{*} p<0.05,{ }^{* *} p<0.01$, and ${ }^{* *} p<0.001$.

\section{Data Availability Statement}

The data that support the findings of this study are available from the corresponding author upon reasonable request.

\section{RESULTS}

\section{Decreased Amount of Visceral Adipose Tissue in Ehd2 ${ }^{-/-}$Mice}

To examine adipocyte function in the EHD2-deficient state,

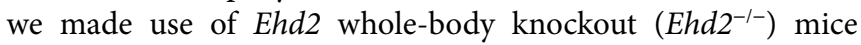
(Matthaeus et al., 2020). Throughout the study, we used corresponding $E h d 2^{+/+}$(WT) mice as control. Western blot analysis from various tissues confirmed global deletion of the EHD2 protein (Figure 1A). Age-matched ( 11-12 weeks) Ehd $2^{-/-}$ mice displayed lower body weight (BW), but similar blood glucose and serum insulin levels compared with WT (Figures 1B-D). We found $E h d 2^{-l-}$ mice to have elevated liver triglyceride levels ( $p=0.064$; Figures 1E,F), a decreased amount of EPI adipose tissue, an increased amount of inguinal (ING) adipose tissue, and trends toward an increased amount of retroperitoneal (RETRO) adipose tissue compared with WT (Figures 1G-I). Further, adipocyte size distribution analysis of EPI and ING adipose tissue revealed similar distribution curves comparing Ehd2-l- and WT mice (Figures 1J,K). These data pinpoint that Ehd $2^{-/-}$mice not only have a trend toward increased liver triglycerides, in line with previous report (Claudia Matthäus et al., 2019), but also have reduced visceral fat mass compared with WT.

\section{Impaired Expansion of Epididymal Adipose Tissue in Ehd2 ${ }^{-/-}$Mice Following HFD-Feeding}

To test if a HFD further aggravated the shifted fat distribution, animals were fed 2 weeks of HFD, which has proven sufficient to induce weight gain and systemic insulin resistance in C57Bl6/J mice (Hansson et al., 2018).
Both Ehd2-l- and WT mice rapidly gained weight to the same extent (Figure 2A), and no differences in food intake, blood glucose, serum insulin, or serum FFAs levels were observed (Figures 2B-E). Glucose and insulin levels increased significantly, and to the same extent, with HFD-feeding compared with chow in both genotypes (shown in Figures 1C,D, 2C,D), which confirms that $\mathrm{C} 57 \mathrm{Bl6} / \mathrm{N}$ mice also are prone to rapidly develop obesity and insulin resistance on a high fat diet. There was a trend toward increased liver triglyceride levels in Ehd $2^{-/-}$mice compared with WT (Figure 2F). Further, Ehd $2^{-/-}$mice fed HFD had a significantly reduced amount of EPI fat tissue, while the ING fat depot was similar with WT (Figures 3A,B). Correlation analysis demonstrated a significant difference in expansion of

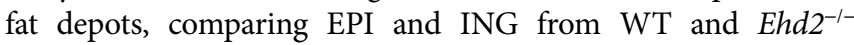
(Figure 3C), whereas RETRO adipose tissue expansion was similar in Ehd2 $2^{-/}$compared with WT (Supplementary Figure S1). Cell size distribution analysis revealed a clear shift in adipocyte size distribution toward larger sizes in response to HFD-feeding in both WT and Ehd2 ${ }^{-l-}$ mice [Figures 3D,E (EPI) and Figures 3H,I (ING)]. Even though, mature adipocytes from Ehd $2^{-1-}$ mice expanded in response to HFD, the distribution curve displayed lower frequency of very small adipocytes and an accumulation of medium-sized adipocytes in Ehd $2^{-/}$compared with WT in the HFD-fed state (Figures 3F,G,J,K).

\section{Decreased PPAR $\gamma$ Activity and Lowered Expression of Caveolin-1 and FABP4 in Adipocytes From Ehd2 ${ }^{-/-}$Mice}

Ligand-activated transcription factor PPAR $\gamma$ is essential for adipogenesis (Rosen et al., 2002). Since EHD2 has been reported to influence transcriptional activity (Torrino et al., 2018), we next assessed if reduced EPI fat tissue expansion could reflect impaired PPAR $\gamma$ activity in Ehd2 ${ }^{-/-}$cells by using a PPAR $\gamma$ response element (PPRE) reporter assay. Indeed, primary EPI adipocytes from chow-fed Ehd $2^{-/-}$mice displayed $60-70 \%$ lower PPAR $\gamma$ activity compared with WT, both in non-stimulated cells, and in cells treated with the PPAR $\gamma$ ligand Rosiglitazone (Figure 4A). Further, by western blot, we detected $\sim 50 \%$ lower levels of FABP 4 (fatty acid binding protein), one of the target genes of PPAR $\gamma$ (Kletzien et al., 1992), in both EPI and ING adipocytes isolated from $E h d 2^{-/-}$mice compared to WT, even though, less pronounced in ING cells following HFD-feeding (Figures 4C,D). The EHD2 knockout was confirmed by western blot using cell lysates and by confocal imaging (Figure 4B). These results suggest that EHD2 influences the transcriptional activity of PPAR $\gamma$ in primary adipocytes, which could explain the impaired expansion of the EPI adipose tissue depot. Possibly, this is due to lowered levels of FABP4 and intracellular fatty acids, the latter acting as endogenous PPAR $\gamma$ ligands, stimulating both lipogenic protein expression and differentiation of new adipocytes. In addition, the impaired response to the synthetic ligand Rosiglitazone in Ehd $2^{-/-}$cells also suggests that PPAR $\gamma$ itself or its co-activators are downregulated.

Further, knock-down of EHD2 is reported to affect the stability of caveolae rather than caveolae density (Moren et al., 2012; Ludwig et al., 2013; Matthaeus et al., 2020). In line with that, we could observe the presence of caveolae in intact adipose tissue from WT and $E h d 2^{-} /^{-}$by electron microscopy (Figure $4 \mathrm{E}$, 
A

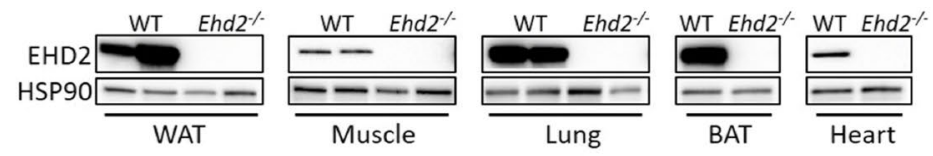

B

C

D
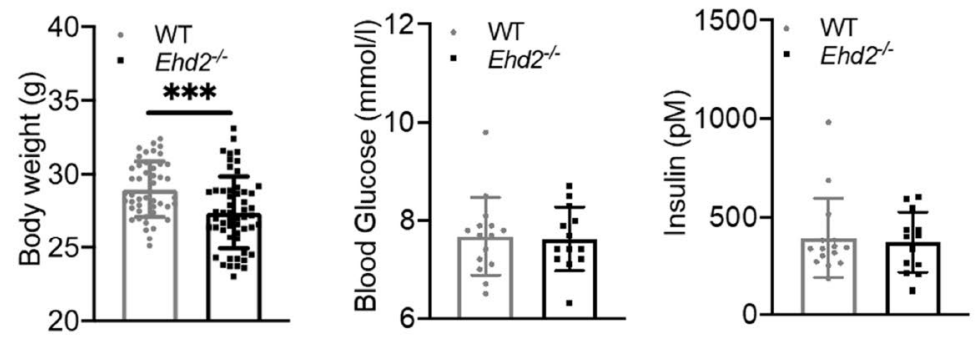

E

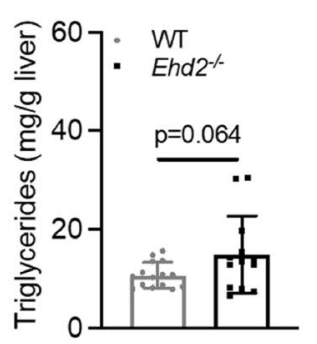

F

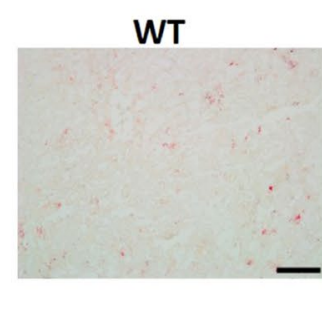

G

EPI

H

ING

I

RETRO
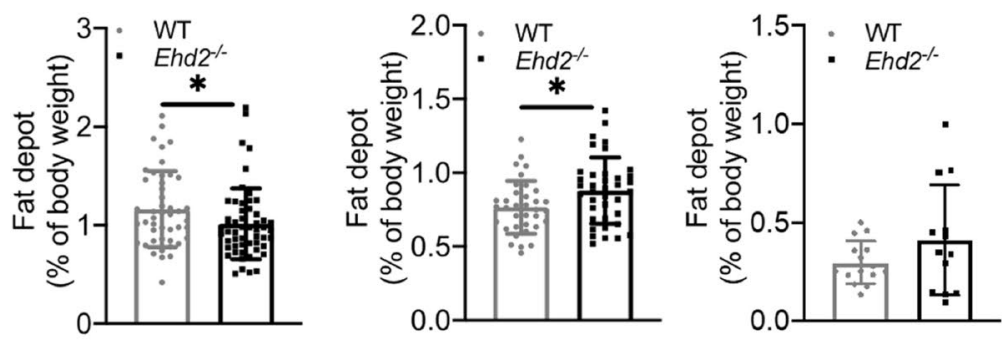

J

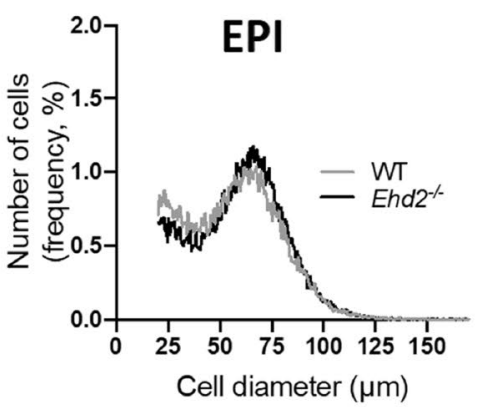

K

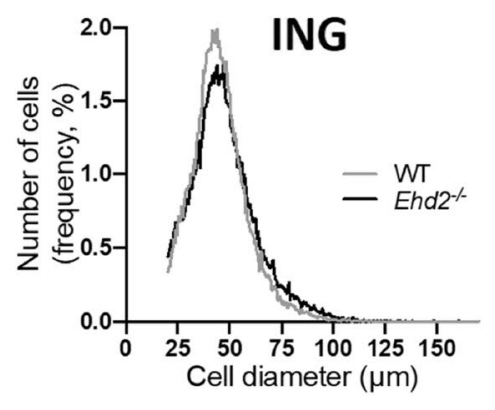

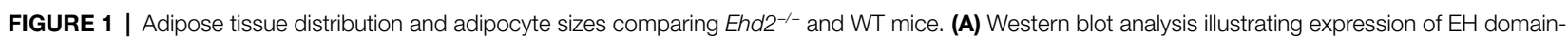
containing 2 (EHD2) in different tissues; white adipose tissue (WAT), skeletal muscle, lung, brown adipose tissue (BAT), and heart from Ehd2 ${ }^{-/-}$and WT mice. Comparison of WT and Ehd2 ${ }^{-/-}$mice fed chow-diet, showing (B) body weight (BW; $n=46-54$ animals/group), (C) blood glucose (mmol/L; $n=13-15$ animals/group), and (D) serum insulin (pM; $n=13-15$ animals/group). (E) Liver triglycerides ( $\mathrm{mg} / \mathrm{g}$ liver; $n=13-15$ animals/group), and (F) illustrated by Oil-Red-O-staining, scale bar $=100 \mu \mathrm{m}$. Adipose tissue depots weights; (G) epididymal (EPI; $n=46-54$ animals/group), (H) inguinal (ING; $n=35-38$ animals/group), and (I) retroperitoneal (RETRO; 13-15 animals/group). (J,K) Adipose cell size distribution of EPI and ING tissue depots analyzed using coulter counter, 6,000 counts/sample, each sample run in duplicate, data displayed as average from $n=3$ samples/group. Data in (B-E,G-I) are presented as mean \pm SD, and $" p<0.05$ and ${ }^{* * * *} p<0.001$ were calculated using unpaired two-tailed Student's $t$-test. 
A

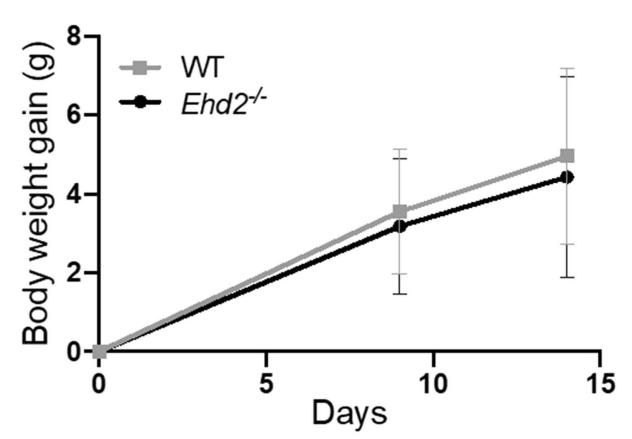

B

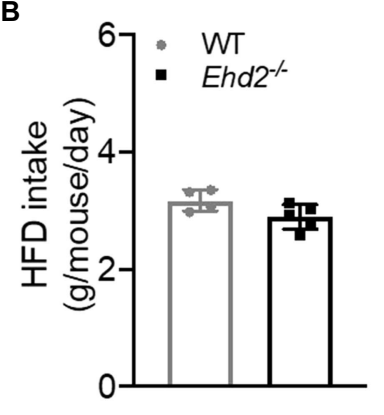

C

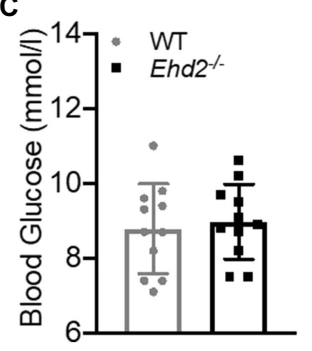

D

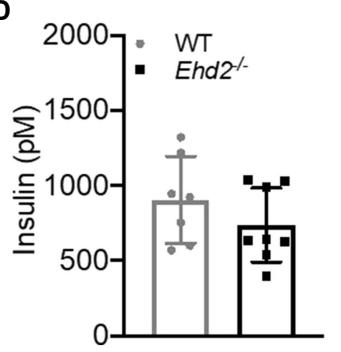

E

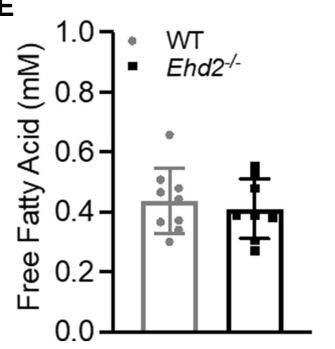

$\mathbf{F}$

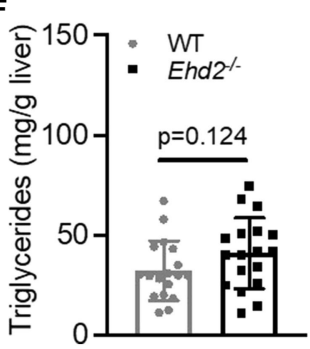

FIGURE 2 | Body weight gain, liver triglycerides, insulin and free fatty acid (FFA) levels in Ehd2-/- and WT mice following 2 weeks of high-fat diet (HFD)-feeding. WT and Ehd2 $2^{-/-}$mice ( $n=18$ animals/group) were subjected to HFD-feeding for 2 weeks, (A) illustrates body weight gain, and (B) food intake (gram/mouse/day). (C) Final blood glucose (mmol/L; $n=11$ ), (D) serum insulin (pM; $n=7-8$ animals/group), (E) serum levels of FFA (mM; $n=8-9$ animals/group), and (F) liver triglycerides (mg/g liver; $n=18$ animals/group). Data in (A-F) are presented as mean \pm SD.

arrows indicate caveolae). Western blot analysis revealed that the main core protein of caveolae, caveolin-1, was reduced $\sim 50 \%$ in adipocytes isolated from EPI and ING adipose tissue in Ehd $2^{-l-}$ mice compared to WT after HFD-feeding (Figures 4C,D). Possibly, the lower caveolin-1 expression could affect the composition or stability of caveolar structures.

\section{Decreased Phosphorylation of Perilipin-1 and HSL, and Decreased Lipolysis in Inguinal Adipocytes From Ehd2 ${ }^{-/-}$Mice}

So far, the data suggest that absence of EHD2 causes impaired expansion of the adipocytes per se and also leads to reduced EPI adipose tissue mass. To investigate whether lack of EHD2 affects intracellular lipid handling, we next focused on lipolysis, the hydrolysis of triglycerides. In the following, lipolysis, measured as the release of glycerol in primary adipocytes, was examined in both non-stimulated (basal) and $\beta$-adrenergic [Isoprenaline (ISO)] stimulated cells. In chow-fed mice, basal but not ISO-stimulated lipolysis was significantly lower in EPI adipocytes from $E h d 2^{-l-}$ mice compared with WT (Figure 5A). In contrast, there was no significant difference in lipolysis in EPI adipocytes isolated after HFD-feeding in either non- or ISO stimulated cells comparing WT and Ehd $2^{-/-}$(Figure 5A). In ING adipocytes, no significant change was observed in chow-fed mice (Figure 5B). Yet, both basal and ISO stimulated lipolysis was significantly reduced $(\sim 50 \%)$ in cells obtained from $E h d 2^{-/-}$mice compared to WT after HFD-feeding (Figure 5B). To further elucidate mechanisms behind reduced lipolysis in ING cells obtained after HFD-feeding, we analyzed the phosphorylation of perilipin-1 and HSL, the main triglyceride lipase. We found that adipocytes from $E h d 2^{-/-}$mice displayed reduced phosphorylation levels of perilipin-1 (pS522) and HSL (pS563) following ISO stimulation (Figure 5C), which is in line with reduced lipolysis (Figure 5B).

Still, the expression of HSL and ATGL was unaltered, whereas total perilipin-1 level was significantly increased $(\sim 30 \%)$ in Ehd $2^{-/-}$adipocytes compared to WT (Figure 5D). Possibly, the latter could reflect an increased lipid droplet surface area since small surface-associated lipid droplets were visible to a larger extent in adipocytes from $E h d 2^{-/-}$mice (Figure 5E).

To test if the reduced lipolysis was caused by impaired signaling at the level of beta adrenergic receptor or adenylate cyclase, we treated cells with dibutyryl-cAMP (DcAMP), a cell permeable, non-degradable cAMP analog. DcAMP activates protein kinase A (PKA) which phosphorylates and activates HSL and perilipin-1, and thereby induces lipolysis. Compared to WT, Ehd $2^{-/-}$adipocytes showed lower lipolysis upon DcAMP treatment (Figure 6A). This suggests that the impaired lipolysis in Ehd $2^{-l-}$ adipocytes occurs downstream of cAMP in the beta adrenergic signaling pathway. Notably, in this set of experiments, we could confirm that also at a very high dose

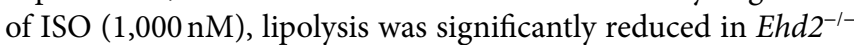
adipocytes. Further, these results are also in agreement with similar gene expression of adrenergic receptors $(A d r 3 b)$ in adipocytes from $E h d 2^{-/-}$mice compared with WT (Figure 6B). The trends toward increased gene expression of Plin 1 mirrors the increased perilipin-1 protein expression shown in Figure 5D. 
A

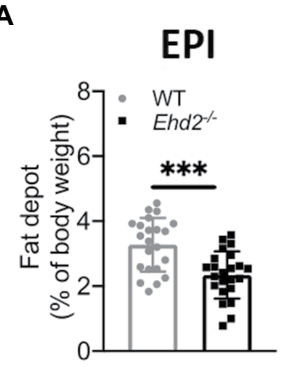

B

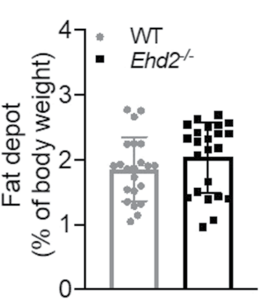

C

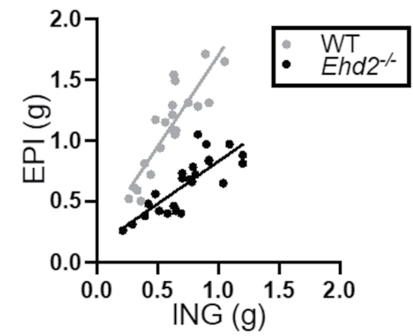

H
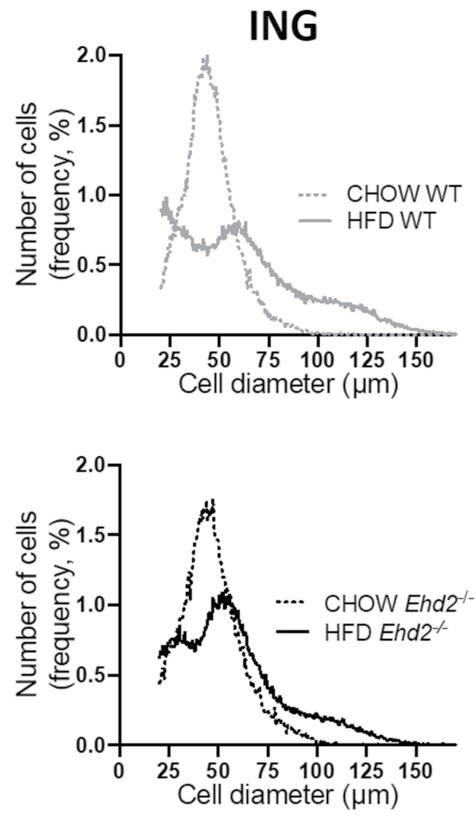

J

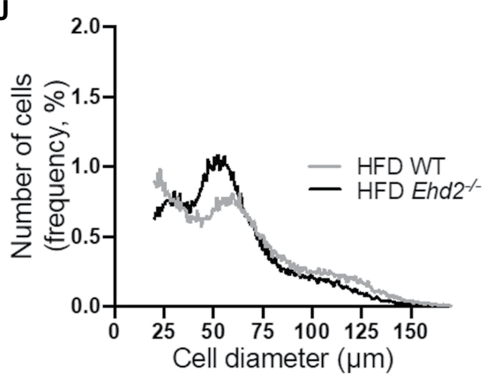

K

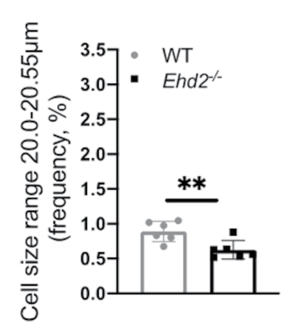

FIGURE 3 | Adipose tissue expansion and adipose cell size distribution in Ehd $2^{-/-}$and WT mice following 2 weeks of HFD-feeding. (A,B) Depot weights of EPI and ING adipose tissue ( $n=22-23$ animals/group) collected after 2 weeks of HFD. (C) Correlation of EPI and ING weight, each symbol (gray=WT, black $=E h d 2^{-/-}$) represent one animal, line shows simple linear regression analysis. Adipose cell size distribution obtained by coulter counter in EPI (D-F) and ING (H-J) depots. Data displayed as average from $n=3$ samples in chow/group, and $n=6$ samples in HFD/group. (G,K) Frequency percentage of small cells (cell diameter 20.00$20.55 \mu \mathrm{m})$ from HFD-fed mice; EPI (G) and ING (K), data obtained from cell size distribution curves, shown in $\mathbf{( F , J ) . ~ D a t a ~ i n ~}(\mathbf{A}, \mathbf{B}, \mathbf{G}, \mathbf{K})$ are presented as mean \pm SD, and ${ }^{* * *} p<0.01$ and ${ }^{* * *} p<0.001$ were calculated using unpaired two-tailed Student's $t$-test. 
A

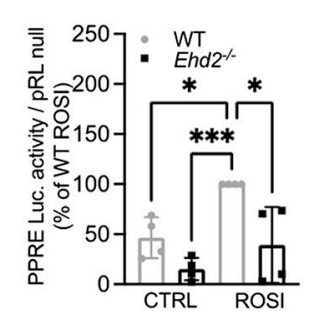

C

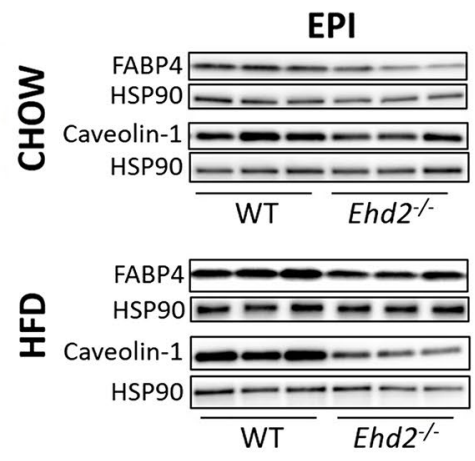

D
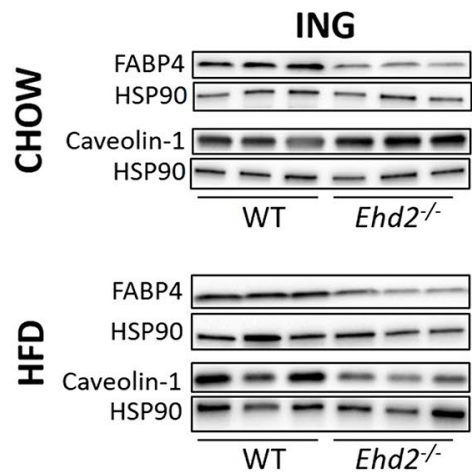

E

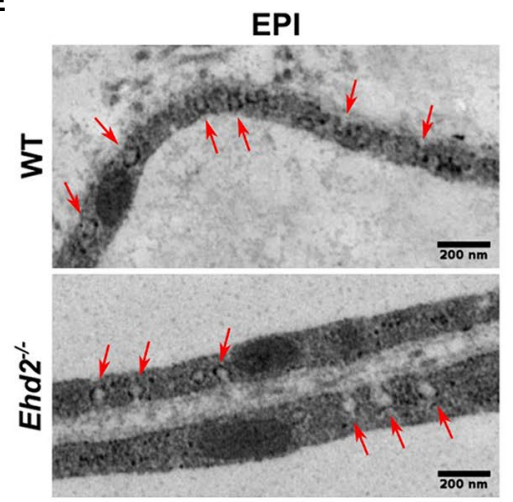

B

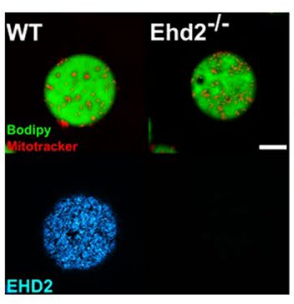

EHD2 $--\infty-2-0$

$\mathrm{FHD}_{2}=-$

HSP9O
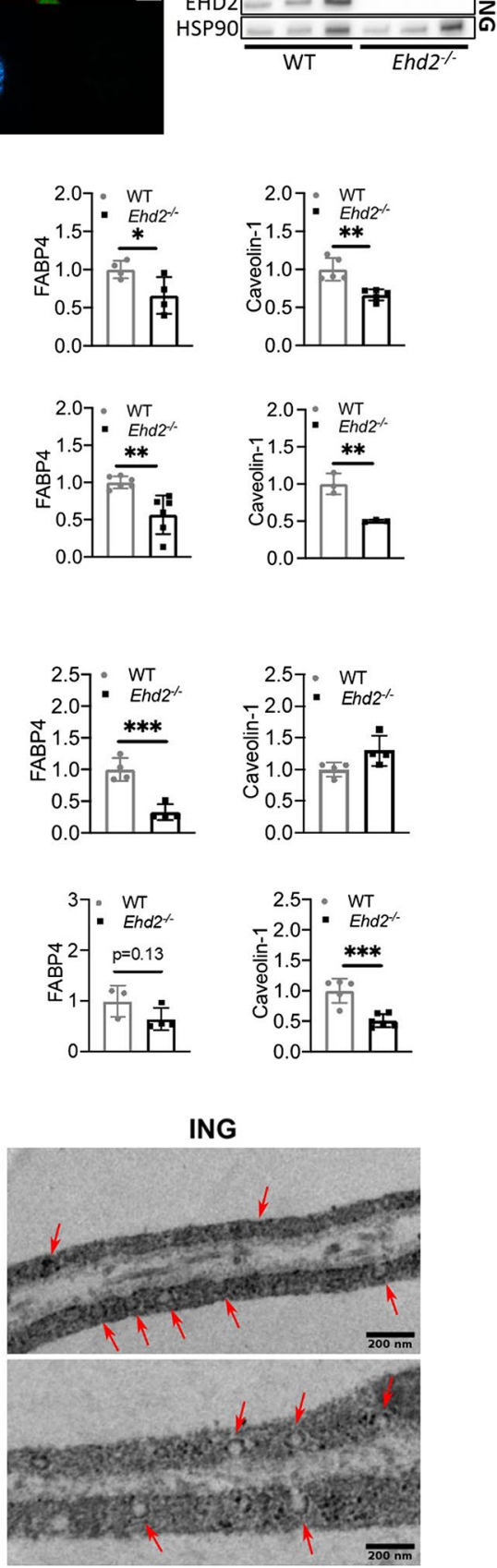

FIGURE 4 | PPAR $\gamma$ activity, FABP4 expression, and caveolin-1 in adipocytes from Ehd2 ${ }^{-/-}$and WT mice. (A) PPAR $\gamma$ activity in primary isolated EPI adipocytes from chow-fed Ehd2 ${ }^{-/-}$and WT mice, non-stimulated or stimulated with rosiglitazone (ROSI) for $24 \mathrm{~h}$ using transfection and dual luciferase assay. Data were normalized to Renilla reporter (pRLnull), and expressed as percentage of ROSI WT ( $n=4)$. (B) Left panel: Confocal image of primary EPI adipocytes from WT and Edh2 ${ }^{-/-}$mice stained for lipids (bodipy, green), mitochondria (Mitotracker, red), and EHD2 (antibody, blue), scale bar $=20 \mu \mathrm{m}$. Right panel: Western blot analysis of EHD2 expression in cell lysates of primary adipocytes isolated from EPI and ING adipose tissue. (C) Representative western blots and quantification of total protein levels of FABP4 and caveolin-1 from primary adipocyte lysates from EPI adipose tissue from chow or HFD-fed mice. HSP90 was used as loading control, $n=3-6 / g r o u p$. (D) Same as in (C) with lysates from ING adipose tissue. (E) Electron micrographs showing the structure and distribution of caveolae at the adipocyte cell membrane in EPI and ING tissue from WT and Ehd $2^{-/-}$animals. Arrows show clearly discernible caveolae. Scale bar $=200 \mathrm{~nm}$. Data in (A,C,D) are presented as mean $\pm S D$, and " $p<0.05$, ${ }^{* *} p<0.01$ and ${ }^{* * * *} p<0.001$ were calculated using one-way ANOVA, Tukey's post hoc test (A), and unpaired two-tailed Student's $t$-test (C,D). 
Fryklund et al.

Lipid Metabolism Is Regulated by EHD2

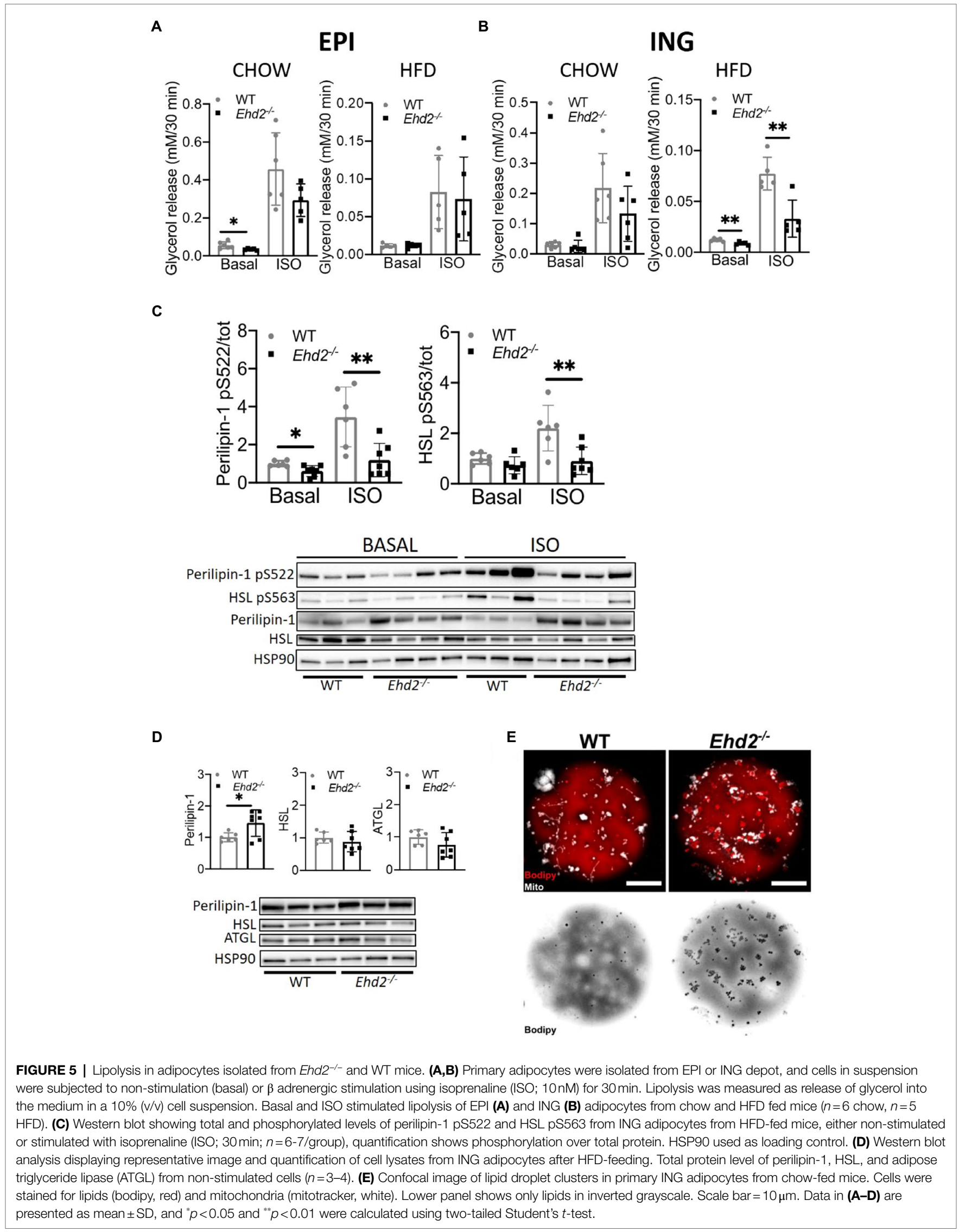

Frontiers in Physiology | www.frontiersin.org

9

September 2021 | Volume 12 | Article 740666 
A

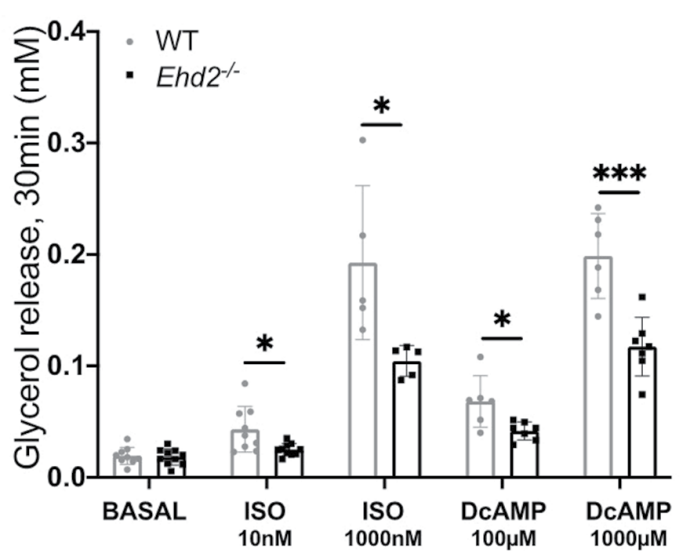

C

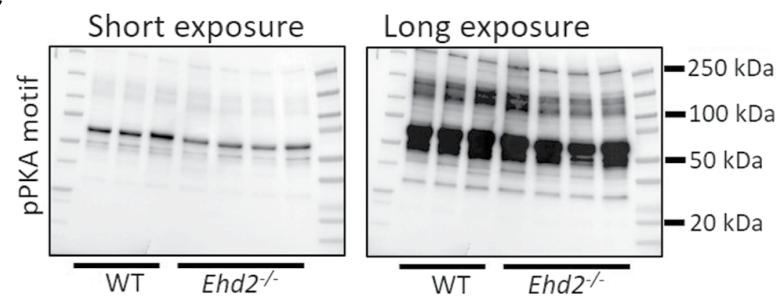

D

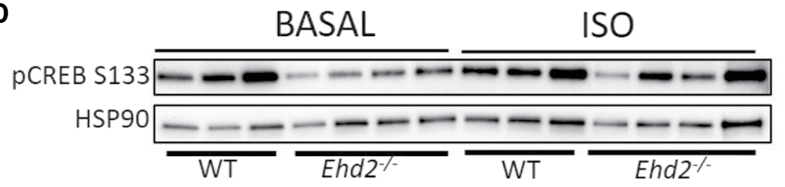

E

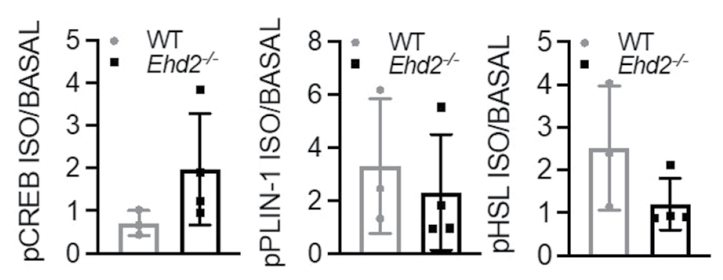

F

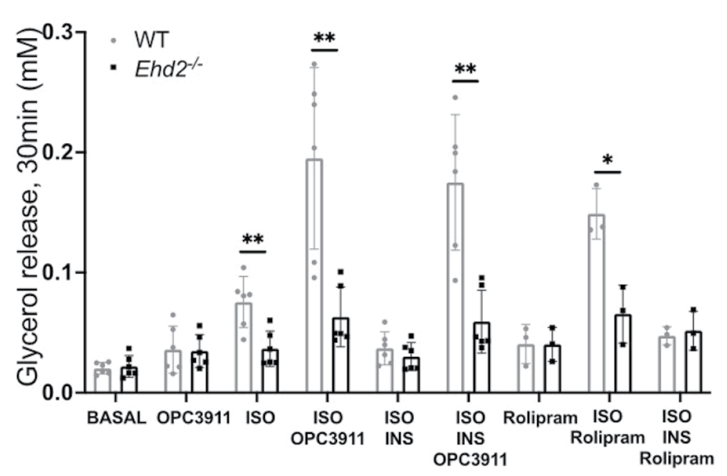

B

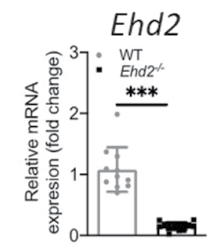

Plin1

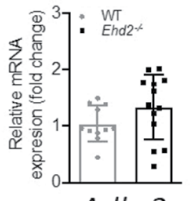

Adbr 3

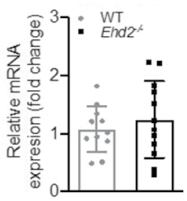

G

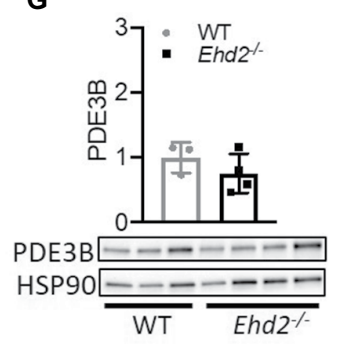

H

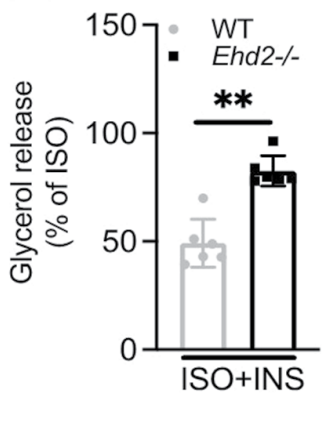

FIGURE 6 | Lipolysis using CAMP analog and PDE-inhibitors in inguinal adipocytes from Ehd2 ${ }^{-/-}$and WT mice. (A) Lipolysis measured as release of glycerol into the medium in a 10\% (V/V) cell suspension using primary adipocytes isolated from the ING adipose tissue depot of HFD-fed mice. Cells in suspension were either non-stimulated (basal), or $\beta$ adrenergic stimulated using isoprenalin (ISO; 10 or 1,000 nM), or stimulated with the non-degradable cAMP analogue dibutyryl cAMP 


\begin{abstract}
FIGURE 6 | (DcAMP; 100 or $1,000 \mu \mathrm{M})$ for $30 \mathrm{~min}$. ( $n=5-8 /$ group). (B) mRNA expression of Plin1, Adrb3, and Ehd2 from ING adipose tissue of HFD fed mice, assessed by RT-qPCR, 18S rRNA used as reference gene, data plotted as relative fold of WT ( $n=11-13 /$ group). (C) Western blot using a phospho protein kinase A (PKA) motif specific antibody [P-RXX(S/T)] in iso-stimulated ING adipocyte lysates from WT $(n=3)$ and Edh2 ${ }^{-/-}(n=4)$ mice on HFD. (D) Western blot showing phosphorylated levels of CREB pS133 in ING adipocytes, either non-stimulated or stimulated with isoprenaline (ISO; 30 min), isolated from HFD-fed mice ( $n=3-4$ / group), HSP90 was used as loading control. (E) Quantification of pCREB pS133 [images shown in (D)], Perilipin-1 pS522 and HSL pS563 (data re-plotted from Figure 5C), expressed as ISO/BASAL. (F) Lipolysis assessed by glycerol release in primary ING adipocytes of HFD-fed mice, where cells in suspension were preincubated for $10 \mathrm{~min}$ with or without PDE3 inhibitor OPC3911 (10 $\mu \mathrm{M})$ or PDE4 inhibitor Rolipram (10 $\mu \mathrm{M})$ followed by 30 min incubation in combination with or without isoprenaline (ISO; 10 nM) and insulin (1 nM). (G) Representative image and quantification of total protein levels of PDE3B from primary ING adipocytes from HFD-fed mice ( $n=3-4$ /group), HSP90 used as loading control. (H) Insulin's ( $1 \mathrm{nM}$ ) anti-lipolytic effect in primary ING adipocytes from HFD-fed mice, data extracted from $\mathbf{( F )}$ and expressed as $\%$ of glycerol release from ISO-stimulated cells ( $n=6 /$ group). Data in $(\mathbf{A}, \mathbf{B}, \mathbf{E}-\mathbf{H})$ are presented as mean \pm SD, and ${ }^{*} p<0.05$, ${ }^{* *} p<0.01$, and ${ }^{* * * *} p<0.001$ were calculated using two-tailed Student's $t$-test.
\end{abstract}

Consistent with the impaired effects of ISO and DcAMP on lipolysis and phosphorylation of HSL and perilipin-1, we found reduced ISO-induced phosphorylation of several PKA targets in adipocytes from $E h d 2^{-l-}$ mice using a phospho-PKA motif specific antibody $[\mathrm{P}-\mathrm{RXX}(\mathrm{S} / \mathrm{T})$; Figure $6 \mathrm{C}]$. Further, we examined the phosphorylation of the cAMP-responsive transcription factor CREB. CREB (pS133) was lower in non-stimulated cells from Ehd $2^{-/-}$mice compared with WT but increased in response to ISO (Figure 6D). In comparison, the fold increase of phosphorylated perilipin-1 and HSL in response to ISO was lower in Ehd $2^{-1-}$ adipocytes, whereas the fold increase of phosphorylated CREB

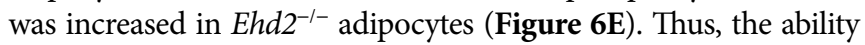
to transmit cAMP-dependent signaling was not compromised for all targets in adipocytes from $E h d 2^{-/-}$mice.

\section{The Anti-lipolytic Effect of Insulin Is Diminished Despite Intact PDE3 Expression and Activity in Adipocytes Isolated From Ehd2 ${ }^{-/-}$Mice}

Next, we investigated if altered expression and activity of PDE3 could explain the impaired lipolysis in ING adipocytes from Ehd $2^{-1-}$ mice. PDE3B is a major PDE family member expressed in adipocytes, responsible for degradation of cAMP. Thus, the expression level and activity of PDE3B have an impact on cAMP mediated signaling events, particularly the anti-lipolytic effect of insulin (Degerman et al., 2011).

The use of a PDE3 inhibitor (OPC3911) increased basal and ISO-mediated lipolysis to the same extent $(\sim 2$-fold $)$ in both genotypes (Figure 6F). We also detected similar protein expression of PDE3B in WT and Ehd $2^{-/-}$adipocytes (Figure 6G). Still, lower lipolysis in ISO-stimulated cells in Ehd $2^{-/-}$adipocytes was observed even in the presence of OPC3911, indicating that increased PDE3B activity is not causing the impaired ISO-mediated lipolysis in Ehd $2^{-/-}$adipocytes (Figure 6F).

Further, we investigated insulin's ability to suppress lipolysis, one of insulin's major metabolic effects in adipocytes. As expected, insulin efficiently suppressed ISO-induced lipolysis in WT ( 50\% reduction; Figure $6 \mathrm{~F}$, same data normalized to ISO are presented in Figure 6H). In contrast, much less suppression was observed in cells from $E h d 2^{-/-}[\sim 25 \%$ reduction (Figures $\left.6 \mathbf{F}, \mathbf{H})\right]$. Further, when co-stimulating with both OPC3911, ISO, and insulin, the anti-lipolytic effect of insulin was lost in WT as expected, but also in Ehd $2^{-/-}$adipocytes (Figure 6F). In comparison, the use of a PDE4 inhibitor, Rolipram, increased ISO-induced lipolysis, but did not abolish insulin's effect in either genotypes (Figure 6F).
Together, alterations of PDE3B expression/activity appear not to contribute to the low lipolysis observed in adipocytes from $E h d 2^{-l-}$ mice. Instead, the data suggest that a defect at the level of, or downstream of PKA, contributes to this phenotype.

\section{DISCUSSION}

In the present study, we demonstrate that lack of EHD2 clearly affects intracellular lipid handling, and the overall storage of excess energy. These effects are well in-line with the first description of the Ehd $2^{-/-}$mouse model, in which EHD2 was proposed to regulate fatty acid uptake in a caveolae-dependent fashion, and lowered EHD2 levels in the obese state were suggested to reflect altered lipid handling (Matthaeus et al., 2020).

We previously identified Ehd2 as one of the highest upregulated genes in adipose tissue during a short-term HFD intervention in mice (Hansson et al., 2018). Later, we confirmed by gene silencing and overexpression in vitro that EHD2 was necessary to sustain adipocyte maturation and lipid metabolism (Moren

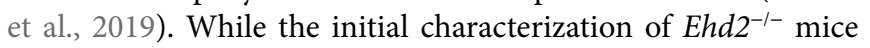
reported increased lipid uptake in cultured adipose cell models differentiated in vitro (Matthaeus et al., 2020), the novel findings in the current study include a marked impairment in lipolysis in primary adipocytes, and reduced expansion of the epididymal adipose tissue depot in Ehd2 $2^{-/-}$mice.

Based on previous knowledge of how EHD2 influences caveolae stability (Moren et al., 2012; Matthaeus et al., 2020), the EHD2-mediated effect on lipolysis is likely dependent on caveolar stability and/or caveolar property. Caveolin-1, the main structural protein of caveolae, is known to scaffold several signal molecules, among those G-protein coupled receptors (Insel et al., 2005). Moreover, adrenergic receptors were reported to be localized at caveolae (Schwencke et al., 1999), and their downstream signaling components to depend on caveolae integrity (Calaghan et al., 2008). The fact that we found lipolysis to be reduced in adipocytes from $E h d 2^{-/-}$also when treated with a cAMP analog (DcAMP), and that the presence of a PDE3-inhibitor did not restore lipolysis, supports that this impairment is to be found downstream of the beta adrenergic receptor and adenylate cyclase. In line with this statement, caveolin-1 was shown to facilitate PKA-mediated phosphorylation of perilipin by bringing PKA physically close enough to fully phosphorylate perilipin in adrenergic-stimulated cells (Cohen et al., 2004). Possibly, the marked reduction of caveolin-1 level in EHD2-deficient cells detected herein could affect spatial 
PKA orientation, which in turn would affect the transmission of cAMP-dependent signaling downstream of PKA. Further, the increased perilipin-1 level in Ehd $2^{-/-}$cells could reflect an increased lipid droplet surface, since we observed an increased number of small surface-associated lipid droplets. The finding that insulin-mediated inhibition of lipolysis was clearly diminished in adipocytes from Ehd $2^{-/-}$compared with WT, despite lower adrenergic stimulated lipolysis, suggests that not only the response to beta adrenergic stimulation but also the response to insulin is hampered in Ehd $2^{-/-}$cells, which definitely is of interest to follow up in future work. Together, we propose that EHD2 is required to sustain signaling events relying on caveolae and interaction with its integral components.

The marked impairment of epididymal adipose tissue expansion in Ehd2 $2^{-l-}$ mice could be caused by impaired adipogenesis, and an inability to increase the adipocyte number and pool of small cells (Faust et al., 1978). In support of this, we found lower proportion of small adipocytes, and that EPI adipocytes had attenuated PPAR $\gamma$ activity, the key driver of adipocyte differentiation (Rosen et al., 2002). Possibly, in adipocytes, EHD2 influences gene expression indirectly by affecting flux of intracellular fatty acids, which serve as PPAR $\gamma$ ligands. This is well in-line with previous reports, where EHD2 was proposed to exert transcriptional control (Torrino et al., 2018). Unfortunately, due to technical limitations, we could not verify PPAR $\gamma$ activity in isolated adipocytes from the inguinal depot. Thus, while primary adipocytes per se could expand despite EHD2 deficiency, the deposit of excess energy was, at the whole-body level, clearly shifted. Indeed, following HFD-feeding, adipogenesis occurs primarily in epididymal and not in inguinal adipose tissue depot (Wang et al., 2013; Jeffery et al., 2015), supporting the hypothesis that differences in depot weight following HFD-feeding in Ehd $2^{-/-}$mice reflect a reduced capacity to promote differentiation.

In contrast, the inguinal adipose tissue depot expanded similar comparing the two genotypes, but still displayed a similar decrease in small adipocytes and increase in medium-sized adipocytes as observed in the epididymal adipose tissue depot. Therefore, the impaired lipolysis in ING adipocytes cannot be explained by an increased pool of hypertrophic cells (Laurencikiene et al., 2011). Rather, depot-specific effects related to caveolar stability or function could explain this, and need to be addressed in future studies. The fact that the most prominent impairment of lipolysis was found in the beta adrenergically stimulated condition, or in experiments, where lipolysis was pharmacologically activated using a cAMP analog, could explain why the inguinal fat mass was

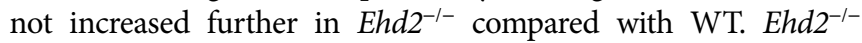
mice's ability to expand the subcutaneous adipose tissue could at least in part explain that similar levels of FFA, insulin, and

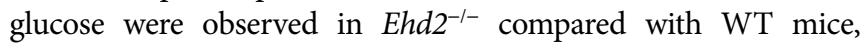
despite slightly elevated liver triglyceride levels.

Taken together, in the present study, we report severe impairments of adipogenesis in the epididymal depot specifically, in EHD2 deficient mice. We also report that EHD2 is an essential component to sustain beta adrenergic lipolysis in inguinal adipocytes, possibly indirectly by influencing caveolae stability and thereby their ability to orchestrate signaling events. Thus, the discovery of EHD2 as an important factor involved in lipid handling in specific adipose tissue depots could provide important insights, necessary to detangle the mechanisms that ultimately limits the cell's ability to store excess energy.

\section{DATA AVAILABILITY STATEMENT}

The raw data supporting the conclusions of this article will be made available by the authors, without undue reservation.

\section{ETHICS STATEMENT}

The animal study was reviewed and approved by Malmö/Lund Committee for Animal Experiment Ethics, Lund, Sweden.

\section{AUTHOR CONTRIBUTIONS}

$\mathrm{KS}, \mathrm{CF}, \mathrm{ED}$, and $\mathrm{BM}$ conceived and designed the experiments. KS, CF, BM, CM, SS, and MG collected, analyzed, and interpreted the data. KS, CF, BM, CM, and ED drafted the article or revised it critically for important intellectual content. All authors made comments on the manuscript and approved the final version submitted for publication.

\section{FUNDING}

This work was financially supported by the Swedish Research Council (2019-00978), Strategic Research Area Exodiab (2009-1039), the Swedish Foundation for Strategic Research (IRC15-0067), Novo Nordisk (NNF17OC0027054 and NNF20OC0063659), Swedish Diabetes Foundation, The Crafoord Foundation, Albert Påhlsson Foundation, Hjelt Foundation, and the Royal Physiographic Society in Lund.

\section{ACKNOWLEDGMENTS}

We would like to thank Oliver Daumke (MDC, Germany) for providing the animals, and Maria Lindahl and Katarzyna Kawka for providing excellent technical support. We would also like to thank Lund University Bioimaging Center (LBIC) for assistance with sample preparation.

\section{SUPPLEMENTARY MATERIAL}

The Supplementary Material for this article can be found online at: https://www.frontiersin.org/articles/10.3389/fphys.2021.740666/ full\#supplementary-material

Supplementary Figure S1 | Expansion of retroperitoneal (RETRO) fat depot following 2 weeks of HFD. Depot weight of RETRO adipose tissue ( $n=22$ animals/ group) collected from HFD-fed mice. Correlation of RETRO weight and body weight gain. Correlation of RETRO weight and epididymal or inguinal weight, each symbol (gray=WT; black $=E h d 2^{-/-}$) represent one animal, line shows simple linear regression analysis. 


\section{REFERENCES}

Acosta, J. R., Douagi, I., Andersson, D. P., Backdahl, J., Ryden, M., Arner, P., et al. (2016). Increased fat cell size: a major phenotype of subcutaneous white adipose tissue in non-obese individuals with type 2 diabetes. Diabetologia 59, 560-570. doi: 10.1007/s00125-015-3810-6

Calaghan, S., Kozera, L., and White, E. (2008). Compartmentalisation of cAMPdependent signalling by caveolae in the adult cardiac myocyte. J. Mol. Cell. Cardiol. 45, 88-92. doi: 10.1016/j.yjmcc.2008.04.004

Cao, H., Alston, L., Ruschman, J., and Hegele, R. A. (2008). Heterozygous CAV1 frameshift mutations (MIM 601047) in patients with atypical partial lipodystrophy and hypertriglyceridemia. Lipids Health Dis. 7:3. doi: 10.1186/1476-511X-7-3

Claudia Matthäus, I. L., Kunz, S., Jonas, W., Melo, A. A., Lehmann, M., Larsson, E., et al. (2019). EHD2-mediated restriction of caveolar dynamics regulates cellular lipid uptake. bioRxiv [Preprint]. doi: 10.1101/511709

Cohen, A. W., Razani, B., Schubert, W., Williams, T. M., Wang, X. B., Iyengar, P., et al. (2004). Role of caveolin-1 in the modulation of lipolysis and lipid droplet formation. Diabetes 53, 1261-1270. doi: 10.2337/diabetes.53.5.1261

Cohen, A. W., Razani, B., Wang, X. B., Combs, T. P., Williams, T. M., Scherer, P. E., et al. (2003). Caveolin-1-deficient mice show insulin resistance and defective insulin receptor protein expression in adipose tissue. Am. J. Phys. Cell Physiol. 285, C222-C235. doi: 10.1152/ajpcell.00006.2003

Daumke, O., Lundmark, R., Vallis, Y., Martens, S., Butler, P. J. G., and McMahon, H. T. (2007). Architectural and mechanistic insights into an EHD ATPase involved in membrane remodelling. Nature 449, 923-U915. doi: $10.1038 /$ nature 06173

Degerman, E., Ahmad, F., Chung, Y. W., Guirguis, E., Omar, B., Stenson, L., et al. (2011). From PDE3B to the regulation of energy homeostasis. Curr. Opin. Pharmacol. 11, 676-682. doi: 10.1016/j.coph.2011.09.015

Faust, I. M., Johnson, P. R., Stern, J. S., and Hirsch, J. (1978). Diet-induced adipocyte number increase in adult rats: a new model of obesity. Am. J. Phys. 235, E279-E286. doi: 10.1152/ajpendo.1978.235.3.E279

Franck, N., Stenkula, K. G., Ost, A., Lindstrom, T., Stralfors, P., and Nystrom, F. H. (2007). Insulin-induced GLUT4 translocation to the plasma membrane is blunted in large compared with small primary fat cells isolated from the same individual. Diabetologia 50, 1716-1722. doi: 10.1007/s00125-007-0713-1

Garcia-Cardena, G., Oh, P., Liu, J., Schnitzer, J. E., and Sessa, W. C. (1996). Targeting of nitric oxide synthase to endothelial cell caveolae via palmitoylation: implications for nitric oxide signaling. Proc. Natl. Acad. Sci. U. S. A. 93, 6448-6453. doi: 10.1073/pnas.93.13.6448

Grunberg, J. R., Hammarstedt, A., Hedjazifar, S., and Smith, U. (2014). The novel secreted adipokine WNT1-inducible signaling pathway protein 2 (WISP2) is a mesenchymal cell activator of canonical WNT. J. Biol. Chem. 289, 6899-6907. doi: 10.1074/jbc.M113.511964

Gustavsson, J., Parpal, S., Karlsson, M., Ramsing, C., Thorn, H., Borg, M., et al. (1999). Localization of the insulin receptor in caveolae of adipocyte plasma membrane. FASEB J. 13, 1961-1971.

Hansson, B., Medina, A., Fryklund, C., Fex, M., and Stenkula, K. G. (2016). Serotonin (5-HT) and 5-HT2A receptor agonists suppress lipolysis in primary rat adipose cells. Biochem. Biophys. Res. Commun. 474, 357-363. doi: 10.1016/j. bbrc.2016.04.110

Hansson, B., Wasserstrom, S., Moren, B., Periwal, V., Vikman, P., Cushman, S. W., et al. (2018). Intact glucose uptake despite deteriorating signaling in adipocytes with high-fat feeding. J. Mol. Endocrinol. 60, 199-211. doi: 10.1530/JME-17-0195

Insel, P. A., Head, B. P., Patel, H. H., Roth, D. M., Bundey, R. A., and Swaney, J. S. (2005). Compartmentation of G-protein-coupled receptors and their signalling components in lipid rafts and caveolae. Biochem. Soc. Trans. 33, 1131-1134. doi: $10.1042 /$ BST0331131

Jeffery, E., Church, C. D., Holtrup, B., Colman, L., and Rodeheffer, M. S. (2015). Rapid depot-specific activation of adipocyte precursor cells at the onset of obesity. Nat. Cell Biol. 17, 376-385. doi: 10.1038/ncb3122

Kim, C. A., Delepine, M., Boutet, E., El Mourabit, H., Le Lay, S., Meier, M., et al. (2008). Association of a homozygous nonsense caveolin-1 mutation with berardinelli-seip congenital lipodystrophy. J. Clin. Endocrinol. Metab. 93, 1129-1134. doi: 10.1210/jc.2007-1328

Kletzien, R. F., Foellmi, L. A., Harris, P. K., Wyse, B. M., and Clarke, S. D. (1992). Adipocyte fatty acid-binding protein: regulation of gene expression in vivo and in vitro by an insulin-sensitizing agent. Mol. Pharmacol. 42, $558-562$.

Laurencikiene, J., Skurk, T., Kulyte, A., Heden, P., Astrom, G., Sjolin, E., et al. (2011). Regulation of lipolysis in small and large fat cells of the same subject. J. Clin. Endocrinol. Metab. 96, E2045-E2049. doi: 10.1210/jc.2011-1702

Li, Y., Periwal, V., Cushman, S. W., and Stenkula, K. G. (2016). Adipose cell hypertrophy precedes the appearance of small adipocytes by 3 days in C57BL/6 mouse upon changing to a high fat diet. Adipocytes 5, 81-87. doi: $10.1080 / 21623945.2015 .1128588$

Liu, L., Brown, D., McKee, M., Lebrasseur, N. K., Yang, D., Albrecht, K. H., et al. (2008). Deletion of Cavin/PTRF causes global loss of caveolae, dyslipidemia, and glucose intolerance. Cell Metab. 8, 310-317. doi: 10.1016/j. cmet.2008.07.008

Livak, K. J., and Schmittgen, T. D. (2001). Analysis of relative gene expression data using real-time quantitative PCR and the 2(-Delta Delta C(T)) method. Methods 25, 402-408. doi: 10.1006/meth.2001.1262

Lizunov, V. A., Lee, J. P., Skarulis, M. C., Zimmerberg, J., Cushman, S. W., and Stenkula, K. G. (2013). Impaired tethering and fusion of GLUT4 vesicles in insulin-resistant human adipose cells. Diabetes 62, 3114-3119. doi: 10.2337/ db12-1741

Ludwig, A., Howard, G., Mendoza-Topaz, C., Deerinck, T., Mackey, M., Sandin, S., et al. (2013). Molecular composition and ultrastructure of the caveolar coat complex. PLoS Biol. 11:e1001640. doi: 10.1371/journal.pbio.1001640

Matthaeus, C., Lahmann, I., Kunz, S., Jonas, W., Melo, A. A., Lehmann, M., et al. (2020). EHD2-mediated restriction of caveolar dynamics regulates cellular fatty acid uptake. Proc. Natl. Acad. Sci. U. S. A. 117, 7471-7481. doi: $10.1073 /$ pnas.1918415117

McLaughlin, T., Lamendola, C., Liu, A., and Abbasi, F. (2011). Preferential fat deposition in subcutaneous versus visceral depots is associated with insulin sensitivity. J. Clin. Endocrinol. Metab. 96, E1756-E1760. doi: 10.1210/ jc.2011-0615

McLaughlin, T., Sherman, A., Tsao, P., Gonzalez, O., Yee, G., Lamendola, C., et al. (2007). Enhanced proportion of small adipose cells in insulin-resistant vs insulin-sensitive obese individuals implicates impaired adipogenesis. Diabetologia 50, 1707-1715. doi: 10.1007/s00125-007-0708-y

Meshulam, T., Simard, J. R., Wharton, J., Hamilton, J. A., and Pilch, P. F. (2006). Role of caveolin-1 and cholesterol in transmembrane fatty acid movement. Biochemistry 45, 2882-2893. doi: 10.1021/bi051999b

Moren, B., Hansson, B., Negoita, F., Fryklund, C., Lundmark, R., Goransson, O., et al. (2019). EHD2 regulates adipocyte function and is enriched at cell surface-associated lipid droplets in primary human adipocytes. Mol. Biol. Cell 30, 1147-1159. doi: 10.1091/mbc.E18-10-0680

Moren, B., Shah, C., Howes, M. T., Schieber, N. L., McMahon, H. T., Parton, R. G., et al. (2012). EHD2 regulates caveolar dynamics via ATP-driven targeting and oligomerization. Mol. Biol. Cell 23, 1316-1329. doi: 10.1091/mbc.E11-09-0787

Palade, G. E. (1953). Fine structure of blood capillaries. J. Appl. Phys. 24:1424.

Pohl, J., Ring, A., Korkmaz, U., Ehehalt, R., and Stremmel, W. (2005). FAT/ CD36-mediated long-chain fatty acid uptake in adipocytes requires plasma membrane rafts. Mol. Biol. Cell 16, 24-31. doi: 10.1091/mbc.E04-07-0616

Razani, B., Combs, T. P., Wang, X. B., Frank, P. G., Park, D. S., Russell, R. G., et al. (2002). Caveolin-1-deficient mice are lean, resistant to diet-induced obesity, and show hypertriglyceridemia with adipocyte abnormalities. J. Biol. Chem. 277, 8635-8647. doi: 10.1074/jbc.M110970200

Rodbell, M. (1964). Metabolism of isolated fat cells. I. Effects of hormones on glucose metabolism and lipolysis. J. Biol. Chem. 239, 375-380. doi: 10.1016/S0021-9258(18)51687-2

Rosen, E. D., Hsu, C. H., Wang, X., Sakai, S., Freeman, M. W., Gonzalez, F. J., et al. (2002). C/EBPalpha induces adipogenesis through PPARgamma: a unified pathway. Genes Dev. 16, 22-26. doi: 10.1101/gad.948702

Salans, L. B., and Dougherty, J. W. (1971). The effect of insulin upon glucose metabolism by adipose cells of different size. Influence of cell lipid and protein content, age, and nutritional state. J. Clin. Invest. 50, 1399-1410. doi: $10.1172 /$ JCI106623

Salans, L. B., Knittle, J. L., and Hirsch, J. (1968). The role of adipose cell size and adipose tissue insulin sensitivity in the carbohydrate intolerance of human obesity. J. Clin. Invest. 47, 153-165. doi: 10.1172/JCI105705

Schwencke, C., Okumura, S., Yamamoto, M., Geng, Y. J., and Ishikawa, Y. (1999). Colocalization of beta-adrenergic receptors and caveolin within the 
plasma membrane. J. Cell. Biochem. 75, 64-72. doi: 10.1002/(sici)1097-4644 (19991001)75:1<64::aid-jcb7>3.3.co;2-c

Shulman, G. I. (2014). Ectopic fat in insulin resistance, dyslipidemia, and cardiometabolic disease. N. Engl. J. Med. 371, 2237-2238. doi: 10.1056/ NEJMc1412427

Smith, U. (1972). Studies of human adipose tissue in culture. I. Incorporation of glucose and release of glycerol. Anat. Rec. 172, 597-602. doi: 10.1002/ ar.1091720401

Stoeber, M., Stoeck, I. K., Hanni, C., Bleck, C. K., Balistreri, G., and Helenius, A. (2012). Oligomers of the ATPase EHD2 confine caveolae to the plasma membrane through association with actin. EMBO J. 31, 2350-2364. doi: 10.1038/emboj.2012.98

Torrino, S., Shen, W. W., Blouin, C. M., Mani, S. K., de Lesegno, C. V., Bost, P., et al. (2018). EHD2 is a mechanotransducer connecting caveolae dynamics with gene transcription. J. Cell Biol. 217, 4092-4105. doi: 10.1083/jcb.201801122

Wajchenberg, B. L. (2000). Subcutaneous and visceral adipose tissue: their relation to the metabolic syndrome. Endocr. Rev. 21, 697-738. doi: 10.1210/ edrv.21.6.0415

Wang, Q. A., Tao, C., Gupta, R. K., and Scherer, P. E. (2013). Tracking adipogenesis during white adipose tissue development, expansion and regeneration. Nat. Med. 19, 1338-1344. doi: 10.1038/nm.3324

Wasserstrom, S., Moren, B., and Stenkula, K. G. (2018). Total internal reflection fluorescence microscopy to study GLUT4 trafficking. Methods Mol. Biol. 1713, 151-159. doi: 10.1007/978-1-4939-7507-5_12
Weyer, C., Foley, J. E., Bogardus, C., Tataranni, P. A., and Pratley, R. E. (2000). Enlarged subcutaneous abdominal adipocyte size, but not obesity itself, predicts type II diabetes independent of insulin resistance. Diabetologia 43, 1498-1506. doi: $10.1007 / \mathrm{s} 001250051560$

Yamada, E. (1955). The fine structure of the gall bladder epithelium of the mouse. J. Biophys. Biochem. Cytol. 1, 445-458. doi: 10.1083/jcb.1.5.445

Conflict of Interest: The authors declare that the research was conducted in the absence of any commercial or financial relationships that could be construed as a potential conflict of interest.

Publisher's Note: All claims expressed in this article are solely those of the authors and do not necessarily represent those of their affiliated organizations, or those of the publisher, the editors and the reviewers. Any product that may be evaluated in this article, or claim that may be made by its manufacturer, is not guaranteed or endorsed by the publisher.

Copyright (๑ 2021 Fryklund, Morén, Shah, Grossi, Degerman, Matthaeus and Stenkula. This is an open-access article distributed under the terms of the Creative Commons Attribution License (CC BY). The use, distribution or reproduction in other forums is permitted, provided the original author(s) and the copyright owner(s) are credited and that the original publication in this journal is cited, in accordance with accepted academic practice. No use, distribution or reproduction is permitted which does not comply with these terms. 